\title{
MAKING A CASE ON SOCIAL INTERACTION OF PARENTS OF CHILDREN WITH AUTISTIC SPECTRUM DISORDERS: A STUDY OF SELECTED COMPOUNDS OF LUSAKA, ZAMBIA
}

\author{
Chalwe Kalumba Hellen ${ }^{1 i}$, \\ Mandyata Joseph ${ }^{2}$, \\ Kasonde-Ng'andu Sophie ${ }^{3}$ \\ ${ }^{1}$ Research Scholar, \\ Zambia Institute of Special Education, \\ Zambia \\ ${ }^{2}$ Research Supervisor, Dr., \\ University of Zambia, \\ Zambia \\ ${ }^{3}$ Research Supervisor, \\ Prof. University of Zambia, \\ Zambia
}

\begin{abstract}
:
Parenting a child is a challenging experience let alone parenting a child with a disability. The nature of the disability in a child goes with its complexity and it often puts parenting skills to the test. This study explores the experiences on social interactions of parents with Autistic Spectrum Disorder (ASD) in selected compounds of Lusaka, Zambia. The study used an interpretative phenomenological framework supported by qualitative approach. In-depth interviews were used to collect data. Non-probability criterion purposive sampling procedure was used to select participants. The sample size comprised of 10 parents with children with ASD. Qualitative data was analyzed thematically. The study revealed that parents had unique experiences in raising their children with ASD. These included; inadequate information on ASD; lack of support services; miscommunications between parents and children with ASD; stigmatization; lack of adequate sleeping time and negative attitude towards parents and their children with ASD. It was evident from the study that parents require supportive services including counselling to enable them to deal with the complexities that emanate from parenting children with ASD. In view of these the study recommended increased awareness on ASD; development, promotion and regular evaluation of intervention strategies parents use aimed at improving the daily lives of parents and their children with ASD in the study sites.
\end{abstract}

Keywords: social interaction; parents; autistic spectrum disorder; lived experiences

i Correspondence: email hellenchalwe78@gmail.com, joseph.mandyata@unza.zm 


\section{Introduction}

The purpose of this study was to gain a deeper understanding of the lived experiences of parents of children with Autistic Spectrum Disorder (ASD) by exploring their everyday lives with itself, their children. Autism itself, is defined as the presence of a marked impairment in development of social interaction and communication with restrictions in activity and interest (Boyd, 2002). Autism is one of several Autistic Spectrum Disorders (ASD) with symptoms ranging from mild to severely devastating. The disorders in the spectrum includes, Asperger's Disorder, Pervasive Developmental Disorders, Autistic Disorders, Rett's Disorders, and Pervasive Developmental Disorders and those not quite Specified or Atypical Autism (Diagnostic and Statistical Manual of Mental Disorders-IV, 1994). Children who have autism are often distant and in different to those around them, have delayed and abnormal language development, tend to display repetitive behaviors, although their mental capacity is quite normal in relation to other children.

Nash, (2003) further, reports that children with ASD may also manifest unusual non-verbal communication techniques, such as eye contact, body postures, gestures, and facial expressions. Their verbal communication can be impaired by their repetitive use of words and abnormal intonation. Their repetitive behaviors may include hand flapping, finger twisting, or complex whole-body movements. Studies have further, noted the different categories of ASD which may developmentally manifest in some children (Neeraja \& Anuradha, 2014). Leo Kanner first described autism in the 1940s when he noticed a subset of children who demonstrated profound isolation and an extreme desire for sameness. In the 1950s and 1960s, theories arose linking ASD to the indifference shown by professional parents (Boyd, 2002). This is no longer considered a legitimate theory for the cause of ASD; however, some parents still believe that they have somehow caused their child's disorders. There are now several hypotheses about the cause of autism; however, no one theory is universally accepted, and the specific cause of autism remains unknown. It is agreed that it probably arises from multiple factors (Boyd, 2002). For reasons that are not completely known, ASD has apparently been on the rise since the late 1980s. The prevalence rates have risen from 2-4 per 10,000 children in the late 1980s to as high as 34 per 10,000 children in a study done in 2003 (Coury \& Nash, 2003).

Autistic Spectrum Disorders are life-long neurodevelopmental disorders characterized by impairments in social interaction and communication and restricted patterns of behavior, interests and activities, with onset in the first 3 years of life. The global prevalence of ASD is reported to be increasing Ruparelia, Abubaka, Badoe (2014) with the most recent estimates for the United States and Zambia inclusive indicating that 1 in every 68 children who are 8 years of age have some form of ASD. However, little is known on the prevalence of ASD in Africa and details of clinical presentations of this disorder remain elusive for this region Reported rates of autistic spectrum disorder have been rising in many countries over the past 2 decades (Wallace, Fein, Rosanoff, 2012). It remains unclear how much of these data represent an actual increase and how much reflect changes in diagnostic definitions and practices, as well as increasing awareness 
among the general public and within the medical profession (Bakare, Munir, BelloMojeed, 2014).

Parenting a child is a challenging experience let alone parenting a child with a disability. The nature of the disability in a child goes with its complexity and it often puts parenting skills to the test. However, as parents learn that their child has a specific disability, they begin a journey that takes them into a life that is often filled with strong opinions and difficult choices (Taderera \& Hall, 2017). Gona, Newton, Rimba, Mapenzi, Kihara, Vijver and Abubakar (2016) acknowledged that the experiences and challenges faced by parents of children with ASD are less reported by African scholars. In its place, the authors note that most of what is reported on the challenges confronting parents of children with ASD, were mainly based on research conducted in Australia, Europe, and North America and less coming from scholars in developing countries (Gona et al., 2016). Notwithstanding the above claim, numerous researches done in western countries, note that living with a ASD child can have profound experiences and effects on the family; particularly the parents including stigmatization, isolation, loss of self-esteem and selfpity and (Leach, 2015; Matenge, 2015; Ceka \& Murati, 2016).

Parents of children with ASD experience a sense of grief, loss, and anger as they learn of their child's diagnosis (Neeraja \& Anuradha, 2014). Gona et al. (2016:2), report that "the stress of living with a child with ASD can affect the psychological and emotional wellbeing of parents and generate conflict between them". Having an ASD child in the family tends to divert the attention of parents particularly the mother from other aspects of the family management (Elford, 2014). Moreover, having an ASD child in the family puts a lot of pressure on the parents' allocation of time and financial resources to their healthy and unhealthy children (Ferguson, 2014). The situation further puts a lot of strain on the parents' parenting practices which often lead to a comprised care and management of ASD children (Heer, 2012). However, this leaves the question of experiences parents of children with ASD have, regarding social interaction with their children.

Zambia is a home to nearly 1.8 million people with disability and has shown a tremendous increase in the population of such people in the last 10 years. (Francis Simui, 2018; CSO, 2018). Given the rapidly rising prevalence of children being diagnosed with ASDs and the increasing rate of reappearance it has become even more important to examine the well-being and adjustment of not only children with the diagnosis, but also their parents and other family members. Despite such an alarming statistics and tremendous increase of ASD in Zambia, there is still lack of awareness on what parents of children with ASD experience regarding social interaction with their children in developing countries like Zambia. While there is a growing body of literature which has explored the impact of other developmental disabilities on Zambian families, there is absolutely little work which has explored the experiences of parents with ASD in relation to social interactions with other children as well as other siblings in the home settings. Studies such as those done by (Daley \& Sigman, 2002; (Chansa-kabali, Nyoni \& Mwanza 2019; Nyoni \& Sepell, 2012) have highlighted autism development countries from an 
education point of view but not necessarily from the experience of parents living and managing children with ASD in the core area of function- social interaction.

\section{Review of Related Literature}

Thwala, Ntinda \& Hlanze (2015) conducted a study which revealed that parents with ASD children at home are confronted with challenges relating to social isolation, emotional stress and depression, grief and financial problems. While the study contributed significantly to understanding experiences of parents in parenting children with ASD, the study did not address the coping strategies that parents were using to manage such children in their respective homes hence, the present study. Contributing on lived experiences of parents, Reeja and Sujatha, (2013) observed that, mothers of children with Down's syndrome and ASD often choice to take full care of their children as opposed to involving other care givers in the daily care and management. The study further reported that, mothers were extremely challenged by the worry about the unpredictable future of their children with ASD. This may be true for the Zambian parents of children with ASD.

Taderera and Hall (2017) reported that having an ASD child in the house may lead to a breakdown in the couple's relationship, which may lead to a divorce. The condition comes with challenging experience in the areas of social interaction and communication with the child which the family may not be able to cope with. Reeja and Sujatha, (2013) note that marriages may fail because of accusations of evil spirits and associated challenges like social interaction when a child with any form of disability is born into a particular household. Stigmatization within the community, has also been stressed in research to be a huge encounter for parents with ASD children. According to Gona et al. (2016), stigma is one of the tough aspects of public encounters experienced by parents of children with ASD. The study further notes that such stigma is worsened by the religious and cultural beliefs within traditional societies, which are not quite positive about the condition itself.

In a study conducted by Dominick (2007), it was observed that Parents often feel overwhelmed by the behavior of children with ASD which makes their relationship with their children sour. This in-spite that, it is their primary responsibility of ensuring that ASD children are accepted in the family. Siblings feel that their parent's attention and love is only for the child with ASD which lead into divisions within the home on how the child with ASD is taken care off. The study further found that the constant attention given to the ASD children can be tremendously upsetting to other children and to parents themselves, leading to mental health issues such as depression, anger and stress, reduced well-being and poor life satisfaction; and in addition, it was found that failure to socially interact with children, was highly experienced by parents when their children with hearing impairment (Mandyata \& Kamukwamba, 2018). This might be true with parents of children with autism. Parents experienced humiliation because others often held offensive thoughts toward children with ASD as well as parents themselves. It was not 
clear from the findings of the study on strategy parents of children with ASD used, hence, the need for present study to explore this aspect.

Abbeduto (2004) conducted a study on views of parents on communicating with ASD children in the United Kingdom. The study revealed that parents fail to comprehend children with ASD in relation to their social interaction, rigidity in thinking as well as behavior, exhibited. Children /adolescents with ASD often portrayed unusual and inappropriate behaviors. These ranged from easily breaking items in homes; being moody behaviors and obsessive-compulsive disorders. Additionally, the study observed that caring for such children with these disorders was demanding on individual parents and the home. The study revealed that, the condition had several comorbidities which result from the behaviors portrayed and impose a huge emotional and economic burden on parents to the ASD children. In the context of the present study, strategies parents were using to manage such unwelcoming behaviors exhibited by children with ASD in homes, were not established.

Although many studies worldwide have clearly shown experiences of parents of children with different developmental disabilities, few studies Gona et al. (2016; Thwala, Ntinda \& Hlanze (2015) in countries abroad, have explicitly focused on experiences of parents of children with ASD with particular focus on their social interaction. It is wellknown that those with ASD have difficulty with such communication and socialization with peers and other members in the family settings. Children with ASD's ability to comprehend the mental states of others (thoughts, intentions, beliefs) for example, to use, predict and understand behavior is deficient thereby interfering with social interaction with parents as well as care givers. It is against this background, the study sought to explore the lived experiences of parents of children with ASD in the context of social interactions.

\section{Problem}

Although a sound understanding of ASD at professional level, the Zambian specialist biomedical professional report of 2016 reports that, parents delay in seeking help because of societal taboos, ignorance and lack of awareness on disability. It is evident from the report, that the experiences and strategies parents use to manage their social interaction of children with ASD, have not been fully understood. Parents both as individuals in their own rights and as caregivers with the ability to maximize the potential of social interaction with an autistic child in home settings, appear to have less understanding of themselves in relation to social interaction with their own children. Less however, is known about the experiences of parents regarding their social interaction as they raise children with ASD. In light of this understanding, the present study sought to address the knowledge gap with regard to experiences of parents in socially interacting with their children with ASD in the Zambian context. It attempted to explore how parents of children with ASD socially interact and interpret their own experiences associated with 
care and managing children with ASD in home settings in selected compounds of Lusaka in Zambia. The study was guided by the following objectives to:

1) establish experiences of parents with regards to social interaction with children with ASD in the home settings,

2) explore the perceived consequences of social interactions with regards to parenting of children with ASD in home settings,

3) ascertain coping strategies parents use when interacting socially with children with ASD children in homes.

\section{Significance}

It is hoped that the findings would be significant because they would have potential of generating interest and awareness on experiences of parents of children with ASD surrounding social interactions in home settings in Zambia, as well as stimulating further investigations. In addition, the findings would also help parents, scholars, local people, policy makers and other stakeholders in improving the welfare of children with ASD through sharing insights on experiences necessary in formulating policies that would enhance the parental and community support to children living with ASD. Lastly, this study might stimulate interest in finding ways and means of improving social interactions between parents and their children with ASD in the study district.

\section{Theoretical Framework}

The Family Life-Cycle Model by Carter and McGoldrick, (1988) explains dysfunction in relation to normal functioning of the family. It frames problems that might arise within the family the course as a system moving through a change and over time. The theory argues that a change in the family affects the life cycle of individuals within the family set up. The foundation of this theory is that families normally go through predictable changes through life events but at times family and individuals such has parents can go through unpredictable events and changes such as taking care of unexpected ASD child. As these changes occur, a family in particular parents of ASD child, must be able to adapt accordingly in order to avoid dysfunction as a result of the care for a differently abled child such as the ASD child. The changes in the family may involve task that must be negotiated as they become complex, bring new roles; operations and put pressure on those close to the child such as parents and other care givers in the home settings. In short, the model believes that everything is in a relationship from the most elementary to the most complex form of organism in the universe. Everything in the universe is affecting something else or is being affected by something else. In the context of the present study, a child with ASD is affecting the life of parents and siblings, while the life of parents and siblings is equally affecting the life of a growing and developing ASD child. They are all in a state of a relationship. With varied experiences. The model was 
therefore seen to be relevant in attempt to understand the experiences of parents of children with ASD in their social interactions with the children at family level.

\section{Topographical Features of Study Site}

Lusaka district is a district in Zambia that lies in Lusaka Province. It is a commercial and government centre (CSO, 2018). It shares its borders with central province on the north and with Southern province on the south. It is the smallest province with an area of 21, $896 \mathrm{Km}^{2}$ and is the most populated and most densely populated. It has a population of 3.3 million of which 2.73 million are in the city itself with a density of about 137 persons per $\mathrm{km}^{2}$ (CS0, 2018). The city itself is one of the urbanized towns in the province as well as the county in Zambia and boasts of an area of 1, $007.6087 \mathrm{~km} 2$ as land reserves and farmland in the peripheries districts. The residential areas in the city itself is classified as low density, medium density and high-density areas with majority of the inhabitants living in the high-density areas of the town. The study was located in the high-density area of the study town.

According to the CSO, (2015), selected socio-economic indicators report Lusaka urban's socio-economic activities centre for majority of people including parents of children with ASD on informal employment in commerce and trade; light industries; agriculture and processing, A few people are in-formal employment. The study town is endowed with business opportunities hence making commerce and trade a major economic activity. However, the district is currently working on reducing the dependency on commerce and trade as the major economic activity by establishing more agricultural related light industries as a way of promoting diversification into other sectors especially agriculture sector (CSO, 2015). As a result, the care and management of children with ASD by parents, from a socio-economic point of view is attributed these sources of income.

\section{Material and Methods}

The study employed an interpretive research design supported by qualitative approaches. The selected research design allowed an in-depth study of experiences of parents with children with ASD in their social interactions in home settings. The study used qualitative methods to generate the required data on lived experiences of parents with ASD children in their core area of functions. Qualitative inquiry, according to Mudau (2004), gives a researcher the opportunity to enter into a person's experience, and by so doing, one gets a different response regarding particular aspects of concern in a study. The ideas, motives, feelings of participants collected led to yielding useful descriptive data to support the study (Holloway \& Wheeler, 2013). The study population consisted of parents with ASD children in Lusaka compounds in Zambia. This population was carefully and purposefully chosen in that had direct involvement with ASD. Due to logistical challenges the study opted to base the study in one district in province instead 
of all 72 districts in the ten provinces in Zambia (Central Statistics Office, 2015 Mid Term Report).

In this study, the sample comprised of 10 participants. All of them were parents of children with ASD. Creswell (2009) indicates that sample size refers to the number of participants selected from the population. The participants were selected until saturation point was reached and recruited for the study in Lusaka urban, Zambia. In this study, purposive sampling procedure was used to select participating parents of children with ASD. Creswell, (2014) states that the power of purposive sampling lies in selecting information rich cases for in-depth analysis related to the central issues under study. This sampling techniques was supplemented by use of snowball arising from information obtained from participating parents as to who also had a child with ASD. The number of participants using purpose sampling technique was not reached. Hence, snowball strategy was applied to help attract more participants to the study. The snowball strategy was based on soliciting the advice and help of the participants who had already agreed to participant in the research project to help put in good words to attract other participants to join the study. In this case the parents of children with ASD were believed to have rich information arising from their experiences on social interaction with their children to support the study. The participants were drawn from three geographical locations within the study site as: low density, medium density and high-density areas. The majority of the parents with children with ASD were drawn from high density areas.

\subsection{Characteristics of Parent-Participants of Children with ASD}

The following were the characteristics of the participating parents; participants were asked to give their age and education levels.

Table 1: Age of Participants

\begin{tabular}{|l|c|c|}
\hline Participants (ID) & Age & Educational Level \\
\hline A1 & 34 & Diploma \\
\hline A2 & 28 & Secondary \\
\hline A3 & 37 & Degree \\
\hline A4 & 27 & degree \\
\hline A5 & 31 & Diploma \\
\hline A6 & 42 & Primary \\
\hline A7 & 29 & Secondary \\
\hline A8 & 44 & Certificate \\
\hline A9 & 36 & Masters \\
\hline A10 & 35 & Degree \\
\hline
\end{tabular}

In relation to age and education levels of the participants, a total of 10 parents of children with ASD participated in this study. Among participates in the study were couples such as A1 and A2; A4 and A5 and A9 and A10. The ages of the parents' range between 28 to 45 years. All the recruited parents had at least one child with ASD although a few had more. 
On the position held in the family and gender of the participants, the pattern was as shown below:

\subsection{Participants Caregiver and Gender}

Table 2: Participants Caregiver and Gender

\begin{tabular}{|l|c|c|c|}
\hline Care giver of ASD children & \multirow{2}{*}{$\begin{array}{c}\text { Total number } \\
\text { of participants }\end{array}$} & \multicolumn{2}{|c|}{ Gender } \\
\cline { 3 - 4 } & 0 & Male & Female \\
\hline Single father & 6 & 0 & 0 \\
\hline Single mothers & 4 & 2 & 6 \\
\hline Couples & 10 & 2 & 8 \\
\hline Total & 10 & 2 \\
\hline
\end{tabular}

Arising from the table above, it was evident that, 6 out of 10 parent-participants where single mothers while, 4 were couples. No single father stayed with a child living with ASD in the sample. Out of 10 parent-participants no single father lived with any of the ASD children. The general findings were that children with ASD were mostly taken care by single mothers as opposed to single fathers. Participants attached the scenario to traditional belief that mothers were responsible for certain disabilities including ASD and that child caring was a gender role for women and of men.

With regard to the geographical location of the parent-participants, the findings were as indicated in the table below:

\subsection{Geographical Location of Parents}

Table 3: Geographical Location of Parents

\begin{tabular}{|l|c|}
\hline Location of Parents & Number of Parents \\
\hline High Density & 6 \\
\hline Medium Density & 2 \\
\hline Low Density & 2 \\
\hline
\end{tabular}

Based on the findings, it was evident that, most of the participants- 6 were drawn from high, follow by those from medium and low-density compounds. In short although not conclusive, most of the parents of children with ASD were found in high density as opposed to other locations in the study town. These findings, however, need not to be generalized or be taken with caution considering the small sample used in the study.

In this study, data was analysed using thematic and content analysis. Data was reduced to themes or categories. Data from interviews was categorised into common emerging themes as a way of understanding what was common in the lived experiences of parents with children with ASD Kasonde-Ng'andu (2013), confirm that the qualitative raw data from interviews, field notes on focused discussions and content analysis should be subjected to the constant comparative analysis technique in order to reach the most significant themes of the topic under study. Kothari, (2011) also observes that other 
considerations would be that which relate to consistency of comments and specificity of responses in follow up probes.

\section{Results}

We now present the results of the study conducted from 2018 to 2021 on experiences of parents of ASD children in their social interactions from home settings in Lusaka urban in Zambia.

\subsection{Experiences of Parents on Interaction with ASD children}

Results based on the first objective are presented in this section. Regarding experiences of parent-participants on interaction socially with their ASD children, from the study, it was evident from the results that, although the locations from which participants were drawn from were different, their experiences on interaction socially with their ASD children were not significantly different. Parents' experiences ranged from: lack of knowledge on how to socially interact with their child; failure to provide social support to child during interaction; constant anxiety and worries on how best to interact with their own children. Further, the study indicated these often led to stressfulness experiences among parents of ASD children.

\subsubsection{Knowledge on Social Interaction}

In order to establish whether or not parent-participants had knowledge on how to socially interact with their ASD children, the study revealed that 9 out of 10 were of the view that they did not have sufficient knowledge on how best to interact socially with their children in home settings. This problem included when their ASD children were diagnosed with the condition as revealed by parent-participants $<\mathbf{A}^{\prime} \mathbf{3}>$ observed that:

\section{Excerpt 1:}

"I had no knowledge on how I should interact with my child with ASD right from time he was diagnosed, I only became knowledgeable about ASD and how to socialize with such a child after constant visits to the hospital and interacting with professionals and advice from service organizations".

In support of these experiences, another parent-participant, $\left\langle\mathbf{A}^{\prime} 7\right\rangle$ expressed ignorance by observing that:

\section{Excerpt 2:}

"I din't know actually how to talk to my child. We did not know socially interact well since I had no idea on how to interact with my child until I started getting support from professionals at the nearby clinic. 
Contributing on the same, another parent-participant $<\mathbf{A}^{\prime} \mathbf{3}>$ had this to say:

\section{Excerpt 3:}

"[Sigh....] actually, I do not understand. He has such a weak social life that most of the time he was worried. He doesn't like to socialize with others in the home. We go to church, and he really doesn't like to mix with friends. He wants to play by himself and only knows me alone really interacting with the child is quite difficult."

Based on these results, it was clear that parents had worrying experiences on how to talk with the children, strengthen their social lives and regularly the much-needed support from professional on how to interact with the ASD children. The parentparticipants did not have sufficient information and skills on how to socially interact with their children.

\subsection{Perceived Consequences of Social Interactions with ASD Children}

On the second objective of the study which was on perceived consequences of the existing experiences on interacting socially with ASD children, the study revealed the following:

\subsubsection{Lack of Social and Emotional Support}

It was imperative to establish parents' experiences on social and emotional support received in home setting as interacts and manages ASD children. The study revealed that, 5 out of 10 parent- participants experienced anger and sadness as a result of their challenges to effectively interact with their ASD children. However, another 5 out of 10 parent- participants experienced relief and became more confident when medical personnel were available to provide professional, social and emotional support. In her contribution to the study, parent-participant $\left\langle\mathbf{A}^{\prime}\right.$ ' $>$ observed that:

\section{Excerpt 4:}

"When we learned that our child had ASD, it was very human, we felt anger, sadness and emotionally broken down. We were always asking what sin we had to committed to have such a child. However, this did not last long, my wife and I agreed to seek guidance and support from the hospital and within 3 months we started understanding; grew emotionally stronger. We were able to socially and emotionally support the child."

A similar sentiment came from another parent-participant $\left\langle\mathbf{A}^{\prime} \mathbf{6}>\right.$ who mentioned that: 


\section{Excerpt 5:}

"I was in shock and denial because of the social stigma that was attached by people around me because of the child. Even those who were friend before I had my child left. This sent me into a state of self-denial until I started to receive support from the clinic."

Adding to the same discussion, another parent-participant, $<\mathbf{A}^{\prime} 4>$ expressed similar feeling by observing that:

\section{Excerpt 6:}

"My world fell apart. It crossed my mind whether I had been a good mother. I cried a lot; a lot of terrible thoughts came in to my mind. I was afraid I'd have a heart attack when I was asked as to why I had such a child outside a shopping mall by a passerby. it was like, I asked myself to have such a child, I cried."

Similar sentiments came from parent- participant $<\mathbf{A}^{\prime} \mathbf{1 0}>$ who mentioned that:

\section{Excerpt 7:}

"I felt an intense rage and then frustration afterwards: Why me? I felt helpless not knowing how to deal with the situation... uncertainly as reported by parent participant."

Contrary to these feelings, some parents experienced a shock, self-denial, sadness and anger, which made it difficulty, to access necessary support to diagnosed children. Parents became better equipped on how dealing with the new challenges arising from the child's condition as gained more and more acknowledgeable in interacting and understanding ASD children. This was supported by one parent-participant, $<\mathbf{A}^{\prime} 5>$ who reported that:

\section{Excerpt 8:}

"For me it was a relief. Because finally I knew what made my child different and I got down to work looking for information and resources everywhere and ways of helping him. I felt that you must try harder, press harder, and take more care of the situation as acknowledged by parents."

In support of this one parent-participant $\left\langle\mathbf{A}^{\prime} 8>\right.$ had this to say: 


\title{
Excerpt 9:
}

\begin{abstract}
"We were prepared for a diagnosis like this. We weren't surprised. We expected it. We just wanted to hear from the doctors what we could do, what treatment we should provide him with as reported by participants, although our awareness did not quite take away our emotions."
\end{abstract}

The notably there were different experiences exhibited by parents which left them emotionally weak over failure to interact with their own children. The reactions ranged from positives such as relief, preparedness over interaction with ASD children to negative experiences such as; misinformation, emotional break down resulting in failure to emotionally support the children as well.

\subsubsection{Inability to Provide Interactive Resources}

Poverty featured strongly as a challenge amongst the parent-participants with ASD children. Parents in the study revealed that they were faced with severe socio-economic conditions which negatively affected ability to interact with children. Thus, parentparticipants are restricted in their help to children to interact well with children. They were unable to socially help rehabilitate their ASD children due to limited interactive resources in home settings. One of the parent-participant $\left\langle\mathbf{A}^{\prime} \mathbf{9}\right\rangle$ added by stating that:

\section{Excerpt 10:}

"...after discovering that our child had autism, we decided to regularly seek support through information and skills on how to deal with social problems of the children. [That] was so helpful to us and the child but the challenge was that we could not afford the required costs to travel to hospital regularly.

It was clear that, some parents are unable to meet the high travelling expenses to and from hospitals to seek for information and acquire skills on how to deal with social interaction with their ASD children.

\subsubsection{Loss of Family Freedom}

Another consequence revealed by the parents was lack of freedom on the parents and other siblings. The study revealed that parents devoted more time to care and attempted to develop positive interactions with the child. Because of this parent were slowly withdrawing from interacting with other people as well as most social activities in the home and the community. As a result of the demand of caring for the children, parents reported role restriction and limitations in pursuing their own a career because of the presence of an autistic child in the home. That was evident in the response of one of the parents- participants $\left\langle\mathbf{A}^{\prime} \mathbf{1 0}>\right.$ who said that: 


\section{Excerpt 11:}

"...freedom is limited for the sake of the child. Every time, I had to be at home to welcome her back from school, socially interact with him. I am afraid to even leave him alone, because of his mental challenge."

The parents explained that it was really difficult for them to travel with their children nor to socialize with them, because of their condition. Each time they did that, they drew more attention from the public, which made them feel rather emotional and as if had lost their freedom in the family.

\subsubsection{Stigmatization and Discrimination}

Stigma and discrimination for children with ASD was revealed as another challenge that interfered with their ability to socialize with parents and other people among them. Parents in the study revealed that society still has not accepted the children with ASD as part of the members in the society who also have needs like all other people thereby affect how parents of such children socially interact with children. This situation seemed to have enormous negative impact on the parents socially because of their children. One parent participant $<\mathbf{A}^{\prime} 6>$ remarked:

\section{Excerpt 12:}

"My child was once discriminated at a family party. I noticed that he was not made to join the other children as they were singing in readiness to cut the cake my child was pushed aside. Even though my child could not talk but he could have mumbled and followed the other children but could not just be accepted by peers. I will not forget that day, but I just kept quiet."

The results above, revealed that it was so hurting to parents of children with ASD upon realizing that their children are mocked and is discriminated by the society. Parents feel that due to stigmatization and discrimination, their children's social adjustment caused isolation or rejection which equally affected parents as well. The majority of the parent-participant, 8 out of 10 believed that they were the ones most affected socially and emotionally by their children's condition. This view was confirmed by one parent-parentparticipant $<\mathbf{A}^{\prime} \mathbf{4}>$ who remarked:

\section{Excerpt 13:}

"It is hard for my child to interact or socialize with her peers and to even visit relatives. Each time we pay a visit to our relatives we had to explain a lot about her social life, ability to interact, emotions. That made me decides not to go with her when visiting our relatives." 
In short, parents as well as ASD children were socially stigmatized and discriminated against. This made it difficult to freely socialized with other people in the neighbor or the community.

\subsubsection{Demand for a Quit Job for Sake of Child}

The study also revealed that, parents were had the bitter choice of having to quit job in order to pay attention and regularly interact with their child. One parent-participant revealed that she decided to leave her job and take care of their child. When probed why she stated that it was because she could not find a suitable house maid for him as most of them could not afford to care for the child due to their behaviour problems. Another parent-participant $\left\langle\mathrm{A}^{\prime} 3\right\rangle$ concurred with the notion of leaving the job for the sake of their child with ASD had this to say:

\section{Excerpt 14:}

"I was working in breweries companies, before finding a place for the child in one of the special schools. I had to leave my job and a promotion in compromise for my son and we had to re-locate for the sake of our son. That was a blow to the family especially on the financial aspect."

It was evident from the results, that because of the demanding nature of caring and socially interacting with ASD children, some parents saw it, as fit to quit certain jobs in preference for those that provide an opportunity to have a quiet time with their children.

\subsection{Coping Strategies on Social Interactions with ASD Children}

The parent-participants were asked to narrate coping strategies employed when dealing with social interaction problems involving with ASD children. The study acknowledged the various approaches used to address challenges coming with social interaction of children with ASD. Through data collected, participants shared some of the strategies used to manage social interaction with ASD children and bringing such interactions as home settings:

\subsubsection{Adjust Activities when the Child Functioned Best}

With regards to managing stress arising from interaction with ASD children, the study revealed that 6 out of 10 of parents tended to give in to demands of the children. This being achieved by accommodating needs of children and sharing thoughts in a calm manner with the children. Additionally, parents made efforts in modifying social environment from time to time to accommodate and make children more interactive. It was also evident that, families provided under the advice of physiotherapists a lot of play materials which encouraged children to freely interact with parents and other siblings in the homes. On managing of non-compliance everyday interactive tasks and activities to 
reduce stress, parents tended to use suctions such not allowing ASD children to play favour right games on the phone, computers nor not accompanying parents to shopping malls. Often these adjustments in activities helped to bring children under control and making the management of children less stressful. These results were supported by views of one parent-participant $\left\langle\mathbf{A}^{\prime} \mathbf{3}>\right.$ who gave the sentiment:

\section{Excerpt 15:}

"We adjust activities to accommodate demands of our child to reduce the risk of unwanted social behavior. This includes doing things at the time of day when the child functioned best, attending events together and taking outings, adjusting expectations depending on our child's mood. It helps reduce anxieties and stress from me as a parent and child as well."

Adding to this view, another parent-participants $<\mathbf{A}^{\prime} \mathbf{1 0}>$ observed that:

\section{Excerpt 16:}

"As parents we have opted to adapt behavioural tokens where when a child's tasks is achieved, we take the child out or give extra time on most favorite game thereby controlling the social behavior of the child."

It was clear from the results that parents used adjustment to activities through modifying environment and use of suctions socially control ASD children, hence reducing stress in parents as they manage the children.

\subsubsection{Reduction of Likelihood of Extreme Disruption}

On attempts to reduce on the likelihood to experience extreme disruptive behavior during social interactions, the study revealed that parents used outings to for example, play parks to avoid risk of outbursts and difficult social behavior from their children. Children saw an outing as having being given freedom which they needed to treasure thereby helping to reduce on chances of unwanted behaviors as parents interact with the children. It was also found that parents at times allowed the children to withdraw or engage in repetitive activities as a way of calming behaviours. These results were supported by one parent- participant <A3> who had this to say:

\section{Excerpt 17:}

"I give in to my child's demands to avoid outburst when in home or public. It helps to minimise unnecessary attention or reduce the likelihood of extreme disruption if my child wants to be too difficult." 
Contributing on the same discussion, another parent-participants observed that:

\section{Excerpt 18:}

"I have come to learn that my child ill-tempered, yells at midnight, you won't believe it, many nights I have driven him around from 21 hours till he sleeps, then I sleep for short hours and go for work. We can't just understand each other at times."

In short, parents used outings and use of repetitive activities to control social behavior of the ASD children.

\subsubsection{Use of Sensory Stimuli Social Environment}

On whether parents used home environment to interact with ASD children, the study revealed that 5 out of 10 parents believed that, creating sensory stimuli type of environment in the home, helped to occupy children for a while, thereby controlling social behaviour. Six out of ten parent-participants reported that through a stimulant home environment, it helped to avoid aversive behavior. This involved avoiding use of noisy machines and minimising exposure to problematic food items which makes children hyperactive. It was also clear that, parents attempted to avoid situations, activities, events, places which appeared to strengthen unwanted behavior. The instead, preferred exposing child environment that motivated or stimulated positive social interaction with parents and other siblings in the home. This view was supported by parent-participant $\left\langle\mathbf{A}^{\prime} \mathbf{5}>\right.$ who reported that:

\section{Excerpt 19:}

"I avoided events that were over-stimulating, or under-stimulating to my child. Social environments which involve feared stimuli, over-excitement; new or different environments tend to limit socially the child or make it difficult for me as a parent to control the child."

Arising from the results above, it was evident that a stimulant environment, avoidance of problematic food exposure to environment through attending events, helped parents to have control over possible unwanted behavior.

\subsubsection{Sticking to Fixed Routines for the Child}

On the issue of routine as a strategy for promoting interactions with ASD children, the study found that, 7 of 10 parents were of the view that, by sticking to fixed routines in daily activities for example, for mealtimes, bedtimes, bathing times, dressing times, parents were able arrest or reduce on incidences of novel or unexpected or outburst behavior from ASD children. It was clear from the study that, maintaining routines for children helped in creating a smooth interaction with ASD child. Contributing on the 
issue of fixed routines as a strategy in the management of social interaction with ASD children, parent-participant $<\mathrm{A} 3>$ had this to say:

\section{Excerpt 20:}

"[...] the days that are the hardest for me, are mondays, the public holidays, even when it was raining, I really had to work hard... to keep my child occupied I opted even to use picture plans or lists to notify my child about upcoming activities, so that he knew exactly what to expect.

Contributing on the same during interview, parent-participant $<$ A2 $>$ observed that:

\section{Excerpt 21:}

"...sometimes I use "social stories" or scripts to model the steps of an activity, or showing my child pictures of new people or places to increase understanding in advance is important in helping my child to accept new things [...] if there's somebody else coming to our home, I have to inform him to avoid a trigger point for a massive meltdown and a complete breakdown in our interactions."

It was evident that, some parents used fixed routines to manage their interactions with ASD children. This involved using social stories, picture of new people likely to visit home and alerting the child of people likely to visit home just ensure that a smooth interaction with the child existed despite changes in the home environment.

\subsubsection{Regular Supervision and Monitoring Child's Activities}

The study sought to establish whether or not parent-participants saw regular supervision and monitoring of children's activities as a strategy in ensuring smooth interaction with ASD children. The responses were varied in that some made efforts to regularly supervise and monitor activities while others were not. The study revealed that parents became more alert to social needs of their children, better informed and ready to intervene in the affairs when, they were in regular contact and monitoring of their children. Parental experience on social interaction with ASD children was as evidenced by contribution of parent-participant $<\mathbf{A} 4>$ who said that:

\section{Excerpt 22:}

"My child has no proper schedule for activities we engage him in at home, if we're lucky to have such it would be easy to interact with him. There is need to keep him busy in [the house] at times we try to feed him ... make sure he's entertaining himself in a quieter way and it works for us to improve interaction. 
From the results, some parents regularly supervised and monitored their children while others did not. Those who regularly were in contact with their children tended to have a smooth interaction than those who did not do so.

\subsubsection{Coaxing and Reward Coping Strategy}

In order to establish how parents coped with non-compliance with everyday tasks and Activities, the study showed that 8 of the 10 parent participants tended to coax their children before they complied and did with given task. Parents intervened or assisted by coaxing the child into doing the daily activities such as dressing, feeding self, taking a bath. The study reported that through use of coaxing strategy, parents were able to minimize likelihood of risk of frustration-related problem behavior in their children. In support of this view, parent-participants $<$ A6 $>$ lamented by saying that,

\section{Excerpt 23:}

"As a result of my daughter's social problems or behaviors, I have to do everything for her, including dressing her, feeding her, and helping her to complete daily hygiene tasks. My child would just lie on her bed looking at the ceiling or wall while holding the clothing in her hand until I go to help her."

In support of this view, parent-participant $<\mathbf{A} 3>$ observed that:

"As a father of ASD child, I have problems with my child who would just sit down and refuse to be moved or play with other children, I have to wait and try to coax him and sometimes I gently persuade him to reduce the likelihood of non-compliance social behaviour."

Contribution on the same, parent participant $<$ A1 $>$ noted that:

"I use reward coping strategy for positive behaviour charts and negotiating to motivate good behaviour and obedience with daily activities. I also praise my child for appropriate behaviour continuing with routine demands despite my child's protests, using a variety of strategies.

Based in the above results, it was clear that some parents were comfortable with use of coaxing and rewards to ensure a smooth interaction with their ASD children. Parents were able to receive some level of compliance when children were coaxed or rewarded for ensuring maintaining acceptable behavior. 


\section{Discussion}

We now present the discussions of the results. Based on the first research objective, results revealed that majority of the parents of children with ASD, were of the view that they did not have sufficient knowledge on the condition and how best to socially interact with their ASD children. It was clear that parents had no adequate knowledge on ASD children and how to care and manage them. This situation forced parents to experience anxiety, inadequacy, loneliness and worry on how best to socially interact with ASD children.

Parents did not know what the problem was and what to do with social problems surrounding with their children. It was for this reason, parents expressed feelings being abounded; discriminated and segregated because of the condition of their children. Some parents felt that the information on nature of their children's condition and how to manage them, could be shared or exposed to them through use of televisions or radio broadcast and social media like Facebook. Parents also felt that information on how to socially interact and support their ASD children, could as well be shared in the community centres like churches. The study believes that, in as much as parents with ASD children remained ignorant of the condition and how to best manage and interact with ASD children prior and after diagnosis and access consultation with a health professional, it remains difficult for parents to ably socialize with their ASD children. The results were in line with the study conducted by Neely-Barnes, et al (2011), who observed that lack of awareness or inaccurate information regarding ASD children prevent, parents from noticing the early signs of ASD and developing workable approaches on how to interact with children.

Haggard's (2010) study in particular, observed that increase in public awareness on ASD, dispel of misconceptions and inaccurate information on the condition and regular exposure of parents to acceptable practices on how to manage the children, had the potential of easing stress parents often when through. Ökcün (2012) reports that, parents had varying levels of agreement on popular topics discussed in the public such as vaccines, dietary restrictions, genetics, prenatal care and social behaviors and management of ASD children. The confusion among parents regarding areas associated social interaction, care and management of ASD children needed more education so to enable parents better understand and interact with children.

With regard to parents' experiences on social and emotional support as they cared for their ASD children, the study revealed that, parent-participants experienced loneliness; anger and sadness as they faced challenges in their efforts to interact and care for ASD children in homes. However, another 1 out of 10 parent-participants experienced relief, focused and became more confident went left to interact with the child as pleased and indeed when medical personnel were available to provide professional, social and emotional support as opposed to people in the neighbourhood and community. These results were in agreement with Chimhenga and Musarurwa (2011) who revealed that some parents do not have knowledge on the children's condition and Lazarevic, \& Kopas-Vukasinovic, (2013) reported that parents were unable to meet the high travelling 
expenses to and from the hospitals to seek professional support on how to care for an ASD child. It is evident from the study that, some parents experienced a shock, selfdenial, sadness and anger and difficulties as interact socially with children. Nonetheless, parents became better equipped on how to deal with the new challenges surrounding interacting with their children.

Poverty featured strongly as a challenge amongst the parent-participants with ASD children. Parents in the study revealed that they were faced with severe socioeconomic conditions which negatively affected ability to interact with professional on children's condition. It was clear that, some parents are unable to meet the high travelling expenses to and from hospitals to seek information and acquire skills on how to deal with condition of the children and effectively social interaction with them. These results agreed with Neely-Barnes et al. (2011), who reported that, parents of children with ASD experienced a powerful societal discourse such discrimination which greatly undervalued their care for Children with ASD resulting into them being emotionally burdened with the issue of how best to interact with ASD children. In a study by Little \& Clark (2006), exploring the experiences of raising a child with Asperger's Syndrome and non-verbal learning disorders, with a specific focus on the joys and worries of parents on the life with children. It was evident that when parents feel involved in raising a child with ASD by being supported and closer interacting from ASD children, they felt positive and joyful in raising such child.

Another consequence revealed by the parents was lack of freedom on the side of parents and siblings as a result of the presence of an ASD child in the home. The study showed that parents devoted more time to care and attempts to develop positive interactions with ASD child at the expense of other siblings in the home. Because of this situation in the home, other siblings slowly started withdrawing from interacting and caring for ASD children. As a result of the demands of caring for the child, parents became restricted and limitations in caring and interaction with the child. Further pursuing of their own a career became also, because of the presence of an autistic child in the home. Further, the study revealed that, stigma and discrimination was another challenge that interfered with their ability to socialize with other parents in the neighbourhood and community.

It was evident, that society still did not accepted the children with ASD as part of the members in the society thereby restricting social interaction. This situation seemed to have enormous negative impact on the parents socially because of their children. In a study by DeMyer (1979), it was reported that, parents were unable to strike a balance between both the kids in the homes and this was viewed as highly stressful by the parents. The parents had feelings of guilt and helplessness as they were unable to give enough time to the other children. The present study seemed to suggest that parent's helplessness and inability to strike a balance between the autistic kid and the typically developing child which led to more parental stressful experiences. This was further completed by stigmatization and discrimination against that limited freely socialization with the child and other people. 
On strategies for managing stress arising from social interactions with ASD children, the study revealed that, parents reported that, as parents they, tended to give in to demands of ASD children. Through accommodating needs of children, it was easy to experience a period of calmness and have fruitful interaction with their children when parents gave in to some demands made by the child. Additionally, in attempt to improve interaction with children, parents made modifications to their home environment by providing toys and other learning materials to accommodate diverse interactive needs. These results are in agreement with those of Dominick et al. (2007) as well as Bearss et al. (2016) who reported that, parents' problematic responses to everyday social interactive situations in children with ASD, was trigged by the environment which was not sensitive to individual needs of children. Contributing child factors ranged from poor social awareness of self, inadequacies in social-information processing to emotional rigidity and intolerance which made it difficult to socially interact with parents and others. Weaknesses in social relationship was evident in triggering environmental contexts, when feared stimuli are present in the context of routine demands; in the absence of parental attention and provision of specific activities when there are changes in routines and environments or when things are not 'on the child's terms. All these factors around the child impaired social interaction with their own parents and other siblings in the home.

On attempts to reduce on the likelihood to experience extreme disruptive behavior during social interactions, the study revealed that parents used outings to for example, to play parks; malls to avoid risk of outbursts and difficult social behavior. ASD children saw an outing as having being given freedom which was hardly experienced in the home and the needed to treasure such freedom reducing on chances of unwanted behaviors likely to make parents not taking them out again. Parents used such rewards to ensure positive social interaction with their ASD children. It was also found that by parents sticking to fixed routines in daily activities such as mealtimes, bedtimes, bathing times, dressing times for arrest or reduce on incidences of novel or unexpected or outburst behavior from ASD children. It was clear from the study that, maintaining routines for children helped in creating a smooth interaction with ASD child. In his study Matenge, (2015) observed that introduction of new things slowly to the child using existing routines helped to improve communication as well as social interaction with the child. These results were also supported by Mandyata (2015) who noted that, introducing things stepby-step, visiting places 'just to look' with the child helped to reduce on stresses experienced by parents and improved social acceptance of their own children.

\section{Conclusion and Recommendations}

By considering the findings of this study, though they may not be generalizable, it is fair to argue that they represent a significant portion of the experiences of parents with regard to their social interaction with ASD children. It was evident that parents of ASD children lived a worrying life over the condition of children and had numerous negative 
experiences on social interaction with their children. They faced numerous challenges on how to socially interact with their own children. These ranged from: lack of social and emotional support, inability to provide interactive resources, loss of family freedom, stigmatizations and discrimination to quitting jobs for the sake of providing social security to their ASD children. It is particularly revealing that parent under diverse experiences in their attempt to socially interact with their ASD children and are willing to adopt different strategies in coping with the challenges posed social interaction with their children if some of these challenges plaguing quality of interaction with the children are address. Based on the results in this conclusion, the following recommendations are made:

1) Parents form, 'parents to parents support groups' share information and learn from each other on how to improve their social interaction with ASD children.

2) Provide capacity building programmes on autism and in particular social interaction for parents of children with ASD and they regularly be organized.

3) Facilitate regular interaction between parents and professionals for the to access support services to enable them develop confidence in caring for ASD children.

4) It equally important to sensitize the communities on the plight of ASD children and their parents for them to be supportive of families with such children.

\section{Conflict of Interest Statement}

The authors declare no conflicts of interests.

\section{About the Authors}

Ms. Hellen Kalumba Chalwe is currently lecturer, research fellow at Zambia Institute of Special Education in Lusaka, Zambia. She is also a part time lecturer with Institute of Distance Education (IDE) under UNZA and currently finalizing her PhD in Educational Psychology with University of Zambia. She holds a Master of Education in Educational Psychology degree, Bachelor of Education in Special Education of the University of Zambia. In addition, she has a Diploma in ICT for Teachers, Diploma in special education and a Certificate in primary Education. Her research interests include: special education; psychology and disabilities.

Dr. Joseph Mandyata is currently a lecturer, researcher in the Department of Educational Psychology, Sociology and Special Education, School of Education, University of Zambia. He has researched and published several articles in the field of special and inclusive education; guidance and counselling in local and international journals. He holds a PhD in Special Education, Master of Education in Special Education and a Bachelor of Arts with Education Degree from the University of Zambia. He lectures in Special Education; inclusive education and guidance and counselling at both postgraduate and undergraduate levels. His research interests are in: policies and management of special / inclusive education; partnerships in education; guidance and counselling, disability, education and poverty. 
Professor Sofie Kasonde-Ng'andu is a professor of Educational Psychology, a Senior Lecturer and researcher in the University of Zambia, School of Education, Department of Educational Psychology, Sociology and Special Education. She holds a PhD degree in Educational Psychology, Master's degree in Educational Psychology and a Bachelor of Arts with Education degree from the University of Zambia. She has published and presented papers on a wide range of educational psychology and related educational issues in local and international journal. Her research interests include equity studies in education, curriculum innovation, teacher education, disability and poverty, psychology of disability, comparative and development education, secondary and primary education and entrepreneurial education.

\section{References}

Barbosa, M. A. M., Chaud, M. N., \& Gomes, M. M. F. (2008). Experiences of mothers of disabled children: A phenomenological study. Acta Paul Enferm, 21(1): 46-52.

Barrow, D. M. (2017). A phenomenological study of the lived experiences of parents of young children with autism receiving special education services. Unpublished doctoral thesis. Portland: Portland State University.

Central Statistical Office (2018). Census of Population and House- demographic survey report. Lusaka, CSO.

Central statistical Office (2015). Selected Socio- economic Indicators Report of 2015. Vol. 11 (2), Lusaka, COS.

Ceka, A., \& Murati, R. (2016). The role of parents in the education of children. Journal of Education and Practice, 7(5): 61-64.

Chimhenga, S., \& Musarurwa, C. (2011). Educating children with special needs: The African context. Retrieved from http://www.savap.org.pk

Cohen, L., \& Manion, L. (2005). Research methods in education (4th ed) London: Routledge.

Creswell, J. W. (2014). Research design, qualitative, quantitative, and mixed methods approaches (4th Ed.). New York: Sage Publications.

Elford, L. M. (2014). Mothers' lived experience of parenting an infant/young child with special needs in a rural context. Unpublished Masters Dissertation. Ontario, Canada: The University of Western Ontario, Canada.

Ferguson, G. (2014). Including children with disabilities in mainstream education: An Exploration of the challenges and considerations for parents and primary school teachers. Unpublished Masters Dissertation. Dublin, Ireland: Dublin Institute of Technology.

Gona, J. K., Newton, C. R., Rimba, K. K., Mapenzi, R., Kihara, M., Vijver, F. V., \& Abubakar, A. (2016). Challenges and coping strategies of parents of children with autism on the Kenyan coast. International Journal of Rural and Remote Health Research, Education Practice and Policy, 16: 1-12. 
Government of Swaziland, (2010). Ministry of education and training education sector policy. Mbabane: Websters Printers.

Green, S. E. (2007). We are tired not sad: Benefits and burdens of mothering a child with a disability. Social Science and Medicine, 64: 150-163.

Heer, K. (2012). The cultural context of caregiving: A phenomenological exploration of the experiences of South Asian careers caring for children with intellectual/developmental disabilities. Unpublished Doctoral Thesis. United Kingdom: The University of Birmingham.

Holloway, I., \& Wheeler, S. (2013). Qualitative research in nursing and healthcare. London UK: John Wiley \& Sons.

Lazarevic, E., \& Kopas-Vukasinovic, E. (2013). The role and place of parents of children with disabilities in inclusive education in Serbia. International Journal About Parents in Education, 7(2): 69-78.

Leach, D. P. (2015). A phenomenological study of the experiences of parents of a child or Children diagnosed with deafness. Unpublished doctoral thesis. Columbia, USA: University of South Carolina - Columbia.

Leedy, P., \& Ormrod, J. E. (2010). Practical research (9th ed.). New Jersey: Pearson Education Inc.

Kasonde-Ngeandu, S. (2013). Writing a Research Proposal in Educational Research, Lusaka, and University of Zambia.

Kothari, C. R. (2011). Research Methodology: Methods and Techniques. New Delhi: New Age International (P) Ltd. Publishers.

Mackelprang, R. W. (2010). Disability controversies: Past, present and future. Journal of Social Work in Disability \& Rehabilitation, 9: 87-98.

Mandyata, J. M. (2015). School and community Partnership in Inclusive Education: An Evaluative Study of Selected Primary Schools in Kasama District of Zambia. PhD Thesis Unpublished. University of Zambia.

Mandyata, J. M. \& Kamukwamba, K. L. (2018). Stakeholders' Views on Use of sign language Alone as a Medium of Instruction for the Hearing Impaired in Zambian Primary Schools. International Journal of Special education, vol.33 (1), 62-76.

Matenge, B. (2015). An exploration of the lived experiences of mothers raising children with autism. Unpublished Masters' dissertation. Cape Town, South Africa: University of Cape Town.

McIntyre, R., \& Hennessy, E. (2012). Experiences of parents of children with attention deficit hyperactivity disorder. Dublin, Ireland: Routledge Taylor and Francis Group.

McMillan, J., \& Schumacher, S. (2010). Research in education. A conceptual introduction. (10 ${ }^{\text {th }}$ Ed.) New York: Addison Wesley Longman.

McNally, A., \& Mannan, H. (2013). Perceptions of caring for children with disabilities: Experiences from Care Givers. Journal of Positive Behavior Interventions, 9(3), 131-150. 
Mungai, E. N. (2014). Challenges facing children with special needs in pursuing education in Thika sub-county, Kiambu County. Unpublished Masters' dissertation. Nairobi, Kenya: University of Nairobi.

Neeraja, P., \& Anuradha, K. (2014). Adjustment problems faced by children with learning disabilities impact of special education. Indian J.Sci.Res, 5(1): 77-81.

Okeke C. I. O. (2014). Effective home-school partnership: Some strategies to help strengthen parental involvement. South African Journal of Education, 34(3): 1-10.

Okeke, C. I. O. \& Mazibuko G. F. (2014a). Inclusion and mainstreaming: Challenges faced Swazi parents of school children with special education needs. Int J Edu Sci, 7(1): 9-20.

Okeke, C. I. O. \& Mazibuko, G. F. (2014b). The experiences of parents of school children with special education needs: An empirical study. Mediterranean Journal of Social Sciences, 5(15): 227-240.

Ökcün, M. Ç., \& Akçin, N. (2012). A description of a mother's play guidance for her child with autism in the process of playing by the rules. Journal of Research in Special Educational Needs, 12(2), 96-106.

Piskur, B., Beurkens, A. J. H. M., Jongmans, M. J., Ketelaar, M., Norton, M., Frings, C. A., Smeets, R. J. E. M. (2012). Parents' actions, challenges, and needs while enabling participation of children with a physical disability: A scoping review. BMC Pediatrics, 12(177): 1- 13.

Reeja, M. R., \& Sujatha, R. (2013). Lived experiences of mothers of children with Down's syndrome in selected schools at Mangalore. Nitte University Journal of Health Science, 3(3): 87-92.

Reynolds, J. D. (2015). A view of parents of children with autism spectrum disorder through Maslow's hierarchy of needs: A phenomenological study. Unpublished doctoral thesis. Lynchburg, VA: Liberty University.

Taderera, C. \& Hall, H. (2017). Challenges faced by parents of children with learning disabilities in Opuwo, Namibia. African Journal of Disability, 6(0), a283. Retrieved from: https://doi.org/10.4102/ajod.v6i0.283.

Neely-Barnes, S. L., Hall, H. R., Roberts, R. J., \& Graff, J. C. (2011). Parenting a child with an autism spectrum disorder: Public perceptions and parental conceptualizations. Journal of Family Social Work, 14(3), 208-225.

Thakran, S. (2015). Learning disabilities: Types and symptoms. International Journal of Applied Research, 1(5): 149-152.

Thwala, S. (2015). Challenges encountered by teachers in managing inclusive classrooms in Swaziland. Mediterranean Journal of Social Sciences, 6(1): 495-500.

Thwala, S. K., Ntinda, K., \& Hlanze, B. (2015). Lived experiences of parents of children with disabilities in Swaziland. Journal of Education and Training Studies, 3(4): 206- 215.

Udoba, H. A. (2014). Challenges faced by teachers when teaching learners with developmental disability. Oslo, Norway: University of Oslo. 
Author(s) will retain the copyright of their published articles agreeing that a Creative Commons Attribution 4.0 International License (CC BY 4.0) terms will be applied to their work. Under the terms of this license, no permission is required from the author(s) or publisher for members of the community to copy, distribute, transmit or adapt the article content, providing a proper, prominent and unambiguous attribution to the authors in a manner that makes clear that the materials are being reused under permission of a Creative Commons License. Views, opinions and conclusions expressed in this research article are views, opinions and conclusions of the author(s). Open Access Publishing Group and European Journal of Education Studies shall not be responsible or answerable for any loss, damage or liability caused in relation to/arising out of conflicts of interest, copyright violations and inappropriate or inaccurate use of any kind content related or integrated into the research work. All the published works are meeting the Open Access Publishing requirements and can be freely accessed, shared, modified, distributed and used in educational, commercial and non-commercial purposes under a Creative Commons Attribution 4.0 International License (CC BY 4.0). 